\title{
AUTOBIOGRAFIA E AUTOFICÇÃO EM MAUS, DE ART SPIEGELMAN
}

Lucas Fazola Miguel $^{1}$

RESUMO: Essa pesquisa tem por objetivo a análise do romance gráfico Maus (2009), de Art Spiegelman, sob o enfoque da escrita de si autobiográfica e autoficcional, bem como da teorização acerca da estruturação narrativa das histórias em quadrinhos. Como referencial teórico, foram utilizadas as obras de Eisner (2013), Garcia (2012), Lejeune (2003; 2008), McCloud (2005), Santiago (2008) e Waldman (2009).

Palavras-chave: Autobiografia; Autoficção; História em Quadrinhos.

ABSTRACT: This research aims to analyze of Art Spiegelman's graphic novel Maus (2009), focusing on autobiography and autofiction writing, as well as theorizing about the narrative structuration of comics. As theoretical reference, the works of Eisner (2013), Garcia (2012), Lejeune (2003; 2008), McCloud (2005), Santiago (2008) and Waldman (2009) were used.

Key-words: Autobiography; Autofiction; Comics.

\section{INTRODUÇÃO}

A Segunda Guerra Mundial se consolidou na história como um dos maiores crimes contra a humanidade, alterando as estruturas políticas e sociais do planeta ao longo do século XX. Potências caíram e surgiram a partir do confronto entre os Aliados e o Eixo, mudando para sempre a vida ao redor do globo. Tal atrocidade resultou em um total de seis milhões de judeus mortos pelas mãos nazistas, seis milhões de trajetórias interrompidas. Se, como diz George Orwell, a história é escrita pelos vencedores, quem escreveria sobre uma tragédia em que o mundo só perdeu?

Art Spiegelman, quadrinista norte-americano nascido na Suécia, se dispôs a assumir esse papel, e escrever em Maus a história do desastre mundial que foi a perseguição nazista aos judeus antes e durante a Segunda Guerra Mundial. Para tanto, o autor optou por narrar o período sob a perspectiva de seu pai, um judeu polonês sobrevivente dos campos de concentração. Lançando mão de uma estrutura intertextual e metalinguistica na composição da história, o autor transformou sua obra biográfica em uma autobiografia que rompe com as

\footnotetext{
${ }^{1}$ Mestrando em Estudos Literários pela Universidade Federal de Juiz de Fora.
} 
barreiras entre o relato confessional e a ficcionalização de fatos reais. No presente trabalho será então analisada a obra de Spiegelman sob o viés autobiográfico e autoficcional, de modo a evidenciar como o fazer literário do autor é impactado pelo inexorável peso do real.

\section{Ratos, gatos e uma autobiografia antropomórfica}

No final dos anos 70, Art Spiegelman deu inicio às pesquisas que posteriormente convergiriam em sua obra de maior destaque, Maus publicado em 1986. De papel, caneta e gravador em mãos, fora em busca do relato de seu pai acerca de sua experiência na Segunda Guerra Mundial. O mergulho no passado de seus pais se mostra também uma tentativa de compreensão acerca do presente do próprio autor em relação a si e sua família.

Nascido poucos anos após o final da segunda guerra mundial, Art Spiegelman não viveu os horrores dos campos de concentração, da miséria e falta de dignidade a que os judeus foram sujeitados pelo Reich. Contudo, o autor teve de conviver com fantasmas que ele mesmo não se via capaz de exorcizar, como a onipresente sombra de Richieu - o irmão mais velho, morto durante a guerra e que ele nunca chegou a conhecer - em sua infância, o suicídio de sua mãe anos após o fim do conflito, e o difícil relacionamento com seu pai. Em Maus, Art Spiegelman busca então uma espécie de reconciliação consigo mesmo e com sua história, de modo que seu relato biográfico da vida do pai toma forma em uma experiência autobiográfica e metalinguistica sem precedentes na história dos quadrinhos.

Publicado primeiramente em edições individuais da revista $R a w$ - editada pelo próprio Art -, no inicio dos anos 80, Maus foi lançada posteriormente em formato de livro convencional, entre 1986 e 1991. O relato de Spiegelman intercala dois planos narrativos, divididos entre o passado da guerra com o período em que um Art já adulto se encontrava com seu pai para registrarem a história, de modo que tal distinção temporal se caracteriza, sobretudo, na esfera da linguagem. O autor não economiza ao retratar a difícil personalidade de seu pai, bem como desde as primeiras páginas já demonstra o comportamento depressivo e autodestrutivo de sua mãe. Spiegelman entrega seus pais ao leitor como figuras reais, falhas e complexas, o que confere ainda mais peso à realidade abordada na narrativa. Desde a já supracitada perda de Richieu, até o suicídio de Anja e o comportamento paranóico de Vladek, 
tudo se deu em decorrência do trauma acarretado pela guerra. Foram essas as marcas indeléveis deixadas por Hitler na família de Art. De acordo com García (2012), pode-se compreender que Maus não trata diretamente da história do Holocausto mas, sobretudo, do legado deixado por ele. A história da vida do autor se funde então à história dos efeitos provocados pelo Holocausto em sua família, e tal conflito entre a construção de sua individualidade e de sua vivência coletiva é evidenciada em cada página da graphic novel. O livro I, intitulado "Meu pai sangra história", inicia-se com uma epígrafe atribuída a Adolf Hitler, que diz: "Sem dúvida, os judeus são uma raça, mas não são humanos". De maneira a ironizar a afirmação do Führer, Spiegelman opta por retratar em sua obra todos os seres humanos como animais antropomorfizados. Judeus são ratos (maus, em alemão), alemães são gatos, poloneses são porcos, e norte-americanos são cachorros, por exemplo. Tal construção mexeu com um dos pilares dos quadrinhos infantis, os funny animals, trabalhando-os alegoricamente em função de uma história crua e realista. Se em um primeiro momento, a abordagem do autor abre margem para a definição de Maus como uma alegoria animal pura e simples, em sua totalidade a obra se coloca como uma narrativa em quadrinhos composta de animais antromorfizados inseridos em um acontecimento de consequências colossais para a humanidade. García (2012) ressalta que em uma história em quadrinhos de funny animals, os animais não apenas se comportam como pessoas, mas de fato são seres humanos, não importando com quais criaturas do reino animal elas se pareçam. Sobre tal abordagem narrativa do autor, Waldman afirma que:

\begin{abstract}
O uso da face animal para os homens talvez se deva ao fato de o passado ser visualmente inacessível ao autor. Assim, como representá-lo através do desenho? Que cara atribuir à vítima e ao perpetrador? Como particularizá-las? Entretanto, não se pode esquecer que o autor, em sua opção por representar os judeus como ratos traz para o corpo de seu trabalho um elemento forte e negativo da figuração que os nazistas faziam dos judeus em cartazes de propaganda, filmes, discurso, etc., associando a essa imagem a noção de sujeira, dejeto deflagrador de epidemia a ser eliminado como medida de higiene. Se a autenticidade realista não estava entre os objetivos de Spiegelman, essa opção poderia sinalizar uma adesão ao inimigo. Mas, ao contrário, o autor desconstrói o modelo de judeu nazista ao atribuir múltiplas qualidades aos ratos: são bons, solidários, ranzinzas, obsessivos, enfim, apresentam qualidades e defeitos, como qualquer ser humano. Neste sentido, o autor implode a construção monolítica e maniqueísta, humanizando a imagem. (WALDMAN, 2009, p. 317)
\end{abstract}

A questão do Real em Maus se mostra preponderante, uma vez que o relato autobiográfico é o alicerce que sustenta toda a condução da narrativa de Spiegelman. O pacto 


\section{A DARANDINA}

autobiográfico, proposto por Lejeune (2008), é consolidado a partir do momento em que há a afirmação da identificação dos papeis do autor, como narrador e personagem da própria obra. O contrato de leitura estabelece-se então, a partir do momento em que Spiegelman evidencia ao leitor que se trata da história de sua vida, bem como de seus pais e de sua esposa.

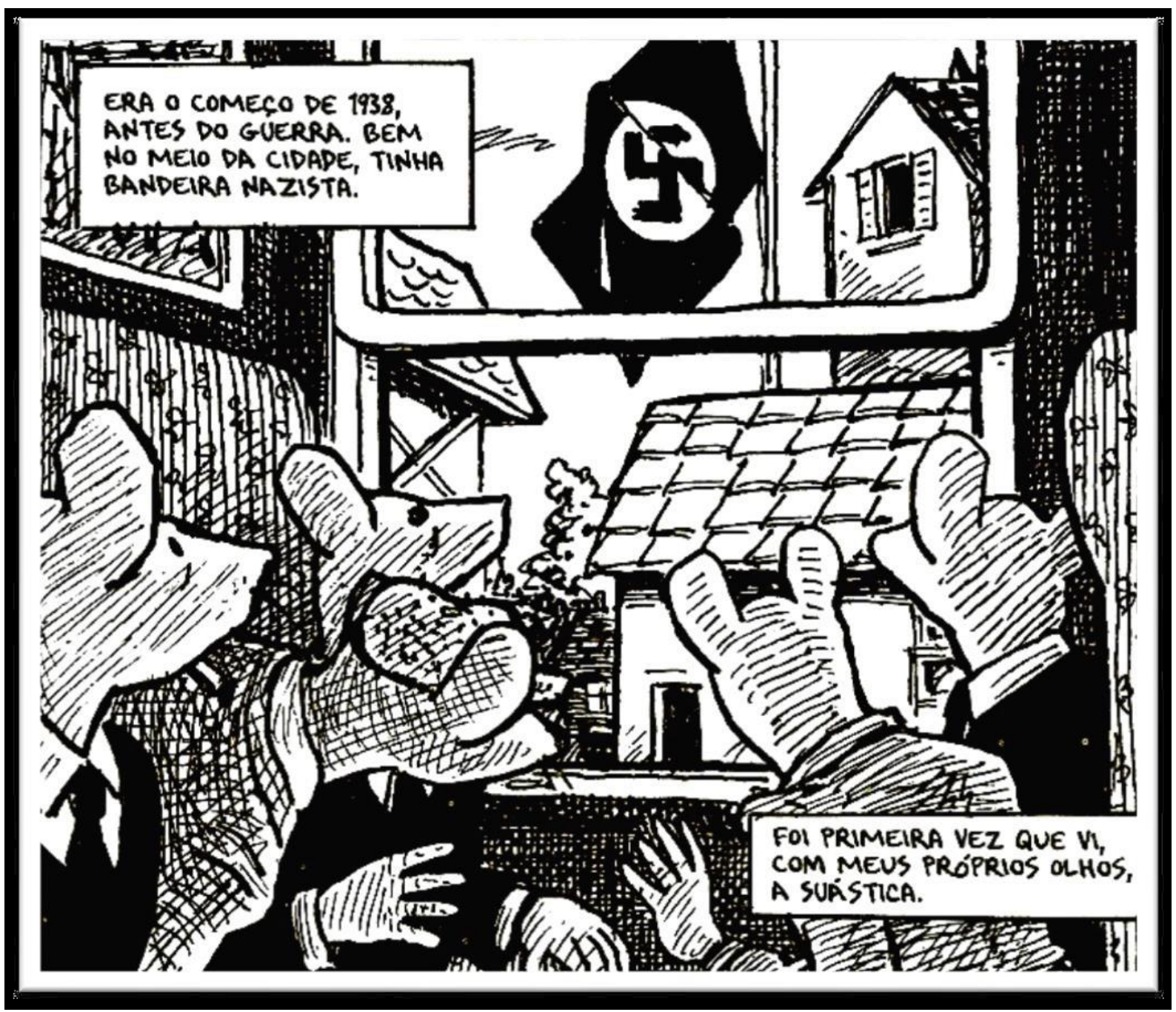

Figura 1: Judeus observando a ascensão do nazismo. (SPIEGELMAN, 2009, p. 34)

$\mathrm{O}$ aspecto jurídico desse contrato de leitura se baseia no princípio de que o autor se compromete a relatar a verdade, e assina o compromisso ao colocar seu nome como personagem. A narrativa de Spiegelman, ainda que iniciada em sua vida adulta, ganhou sua forma em quadrinhos após alguns anos de pesquisa. Seu pai morreu em 1982, o livro I de 
Maus fora lançado em 1986, e o livro II chegou às livrarias apenas em 1991, o que nos faz observar que o Art retratado na graphic novel já não seria mais o Art que o desenhou nos anos subsequentes à coleta de informações. A identidade de Art Spiegelman enquanto autor e também personagem se constrói em cima de um si mesmo com o outro, e não de um mesmo sujeito imutável.

Ao trabalhar um passado brutal e do qual ele não teve acesso direto, o autor demonstra saber que sua obra existe como representação indireta, através da qual podemos enfim nos aproximar de uma realidade cruel demais para se visualizar por si só. Por trás de cada rato antropomorfizado morto em Maus, incontáveis vidas humanas reais foram ceifadas pelo racismo e intolerância nazista, às quais jamais poderemos catalogar e tomar conhecimento. Para saber, contudo, é necessário imaginar, e aí se encontra o objetivo da antropomorfização dos personagens em Maus, nos levar a imaginar de forma direta o que houve nos campos de concentração nazistas, enxergando além da metáfora animal para identificarmos o que houve naquele massacre de proporções incomensuráveis na história humana. Maus possui animais falantes, mas não é uma fábula, não tem personagens unidimensionais e não possui moral da história em seu final. A leitura de Maus se dá da mesma forma como se materializa a vida diante de cada um de nós: de forma crua, direta, fria e sem eufemismos.

As duas linhas temporais utilizadas na estruturação da obra configuram os dois planos distintos de vivência da narrativa. Essa estrutura bifurcada se entrelaça e se intercala, demonstrando uma fluidez típica da oralidade, de modo que a linguagem marca a distinção entre os períodos retratados. Ao fazer uso de um gravador para captar todos os detalhes dos relatos de seu pai, Spiegelman conserva a marca dessa mesma oralidade presente nas falas de um Vladek já idoso. A tradução de Antônio de Macedo Soares, na edição brasileira de Maus, conserva a característica da obra original em inglês, ao mostrar as quebras de discurso, a precariedade das estruturas gramaticais e o sotaque carregado do pai do autor, ao não se expressar em sua língua materna. Ao retratar o passado, as falas de Vladek se mostram bem estruturadas sintaticamente, o que indica que ele naquele momento da juventude estaria falando polonês ou alemão, línguas nas quais tinha mais fluência.

A autobiografia de Spiegelman se constrói a partir dessa interposição de passado e presente, travestida de uma biografia familiar. $\mathrm{O}$ autor busca resgatar seu próprio passado, 
sanar seus próprios conflitos, a partir da experiência pregressa de seus pais. O peso desse passado não revelado sufoca Art, e se mostra parte preponderante da construção de sua personalidade, de modo que é a partir da biografia de seus pais que o autor enxerga possível traçar sua própria autobiografia. Todos os acontecimentos impactantes da vida do autor estão ligados à Segunda Guerra Mundial, e todos eles transformaram algum elemento da constituição de Art Spiegelman enquanto individuo. Para fazer as pazes com sua própria história, ele precisa então estabelecer essas conexões e situá-las nos lugares a que pertencem.

O livro I termina com dois acontecimentos relevantes para o entendimento da narrativa: no passado, com a chegada de Vladek e Anja à temida Auschwitz, e no presente com o autor chamando seu pai de assassino, por este ter jogado fora o diário de sua falecida esposa, Anja, silenciando-a para sempre. Observa-se nesse momento da narrativa que Art desejava obter o ponto de vista da mãe acerca da história, do período de perseguição, de sua experiência em Auschwitz, e do pós-guerra, uma vez que ela constituía parte importantíssima no relato de Vladek, e se mostrara de acordo com os relatos dele, muito mais parecida com o filho do que ele próprio. A impossibilidade de obter todos os aspectos de seu passado familiar deixa o autor fora de si, uma vez que seu trabalho de reconstrução memorial ficará inapelavelmente incompleto sem a outra metade de sua criação, sem a outra parte de sua formação identitária. A discussão que finaliza o livro I evidencia o distanciamento que existe entre ele e sua figura paterna, e prepara o terreno para a arrebatadora parte final de Maus, que viria a ser publicada alguns anos depois.

Ao longo do primeiro livro é sentida a presença invisível de Hitler nos rumos da história. É sua ascensão ao poder que catalisa os eventos que levariam a Alemanha ao massacre judeu, e a mão oculta do Führer conduz toda a tragédia, que torna os protagonistas Vladek e Anja em verdadeiras marionetes do circo de horrores que foi a cruzada antissemita germânica, lutando para sobreviverem tais quais ratos fugindo de gatos, como nas tradições dos clássicos desenhos infantis. A escolha de Spiegelman pelos animais em questão para sua representação da realidade, definitivamente, não foi por acaso. 


\section{a DARANDINA}

revisteletrôn i c a

\section{A ficção do eu e o fazer autobiográfico}

O segundo volume de Maus narra a luta de Vladek e Anja pela sobrevivência em Auschwitz, simultaneamente à luta pela sobrevivência de Art e Françoise com um já idoso e cada vez mais debilitado Vladek. Contudo, só a perspectiva do pai é contada na história da Segunda Guerra, uma vez que, conforme fora supracitado, este queimou os diários da esposa após seu suicídio. Nessa segunda etapa, lançada em 1991, a linha narrativa do presente ganha mais espaço em detrimento ao relato memorial de Vladek, e os conflitos de Art em relação ao pai e sua própria formação identitária são trabalhados pelo autor através da retratação de pequenos embates triviais entre os dois, além de suas divagações junto a sua esposa Françoise.

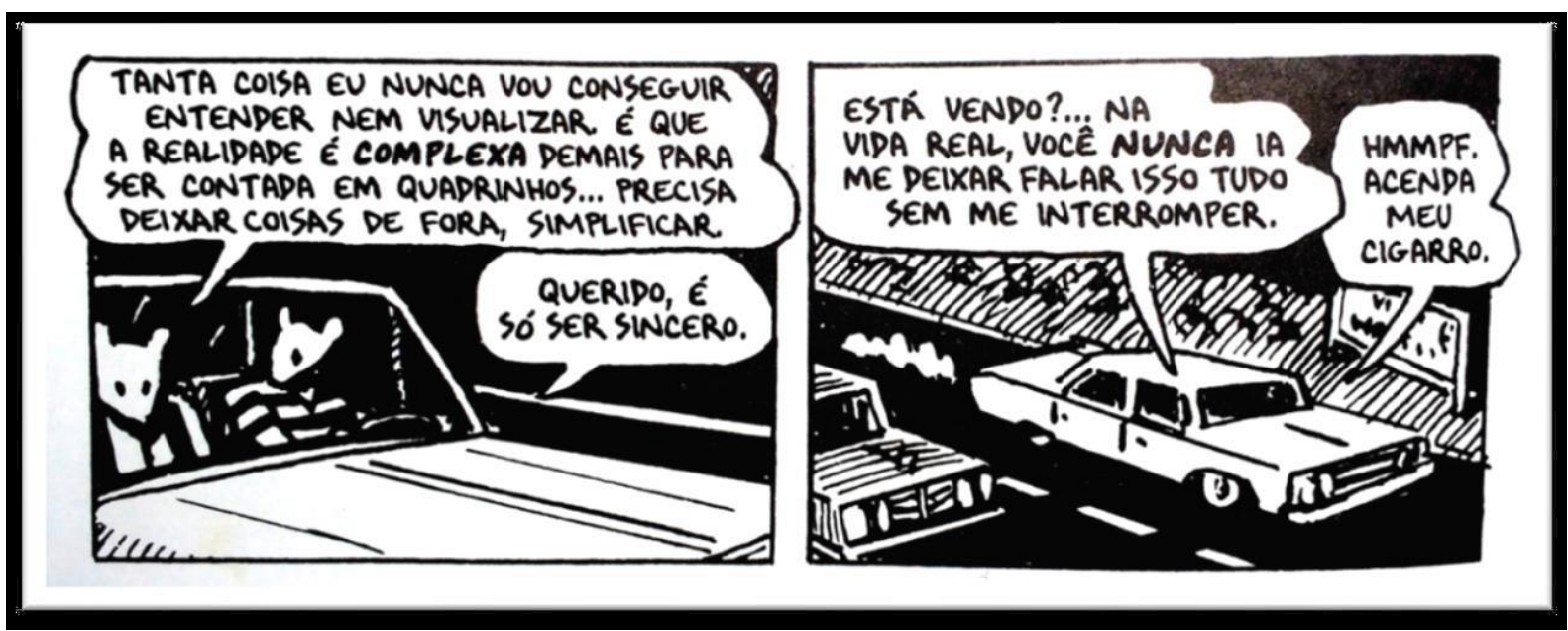

Figura 2: O desabafo de Art demonstra, através da metalinguagem, a distinção entre real e ficcional em sua obra. (SPIEGELMAN, 2009, p. 176)

O maior destaque dado à linha temporal de seu presente narrativo permite a Spiegelman uma acentuada liberdade para lidar com os limites entre o fazer autobiográfico e o ficcional. Schøllhammer (2009) afirma que se pode falar em autoficção quando, sob a camada do fazer ficcional o conteúdo autobiográfico narrado se preserva, simultaneamente intervindo na organização do próprio aspecto ficcional da obra, conscientemente abrandando as fronteiras entre os dois fazeres literários. 


\section{a DARANDINA}

revisteletrôn i c a

Na escrita de si, Santiago (2008) demarca quatro pilares constitutivos: a experiência, a memória, a sinceridade e a verdade poética. Tais bases estão demarcadas de maneira preponderante na obra de Spiegelman, uma vez que seu objeto narrativo se consolida a partir de sua própria história pessoal e familiar, entrelaçada com uma catástrofe de proporções colossais. A desconstrução conceitual do "humano", executada pelo autor ao antropomorfizar faces animais como representações de pessoas existentes no mundo real, visa adquirir distanciamento suficiente na recepção de sua narrativa, de modo que seja abordada a experiência de vida cruel daquele recorte de tempo, resgatada através das memórias de seu pai, sem omitir as características que o tornam um ser humano falho, tal qual o é o homem da vida real.

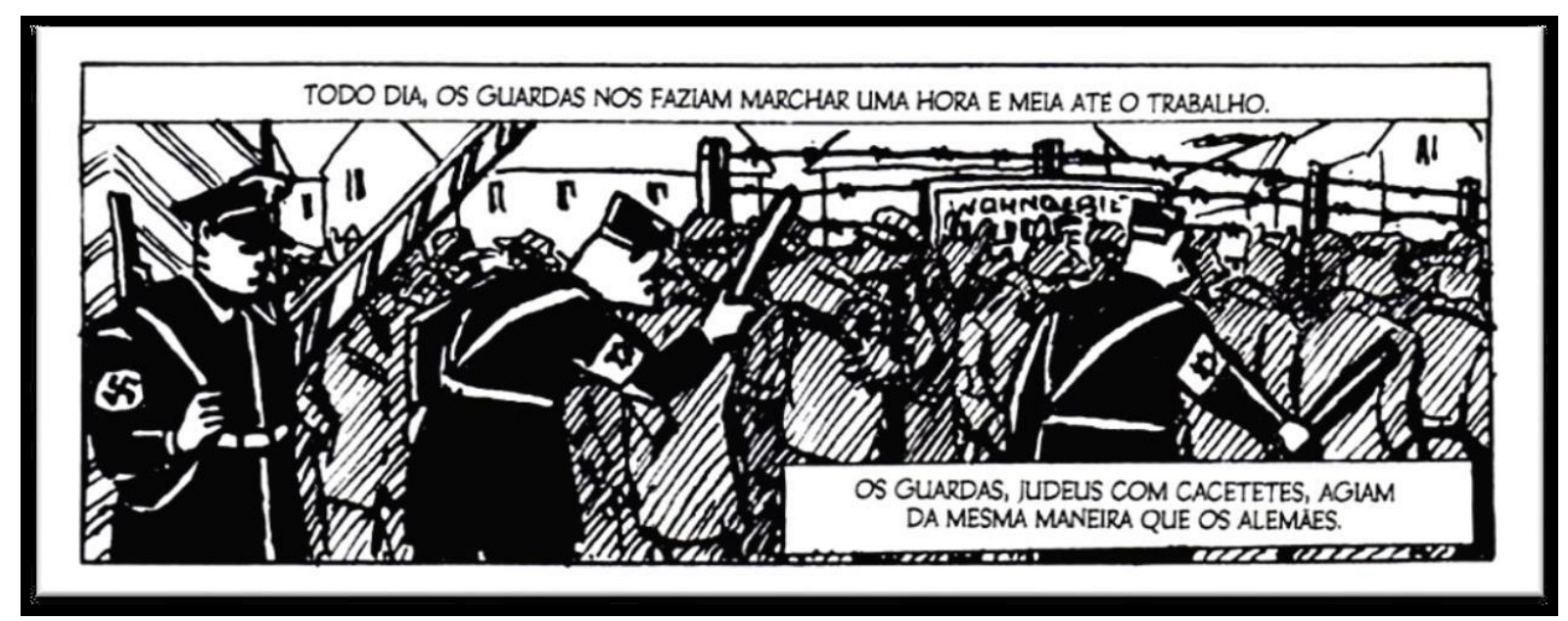

Figura 3: Início da segregação imposta pelos nazistas aos judeus. (SPIEGELMAN, 2009, p. 108)

De acordo com a definição elaborada por McCloud (2005), as histórias em quadrinhos se caracterizam pela conjugação de imagens pictóricas e outras que são colocadas justapostas em sequência deliberada, com o objetivo de transmitirem informações e/ou produzirem alguma reação no espectador. Tal construção se estabelece a partir da hibridização entre discurso pictórico e verbal, e ao lançar mão desse meio para trabalhar sua narrativa, Spiegelman ressemantiza a si mesmo enquanto sujeito da narrativa, bem como aos demais personagens que compõem seu relato, conferindo para cada criação antropomórfica sua, fragmentos autobiográficos de validação memorial, construídos sob uma roupagem artisticamente distinta de suas contrapartes no mundo real. Eisner (2013) destaca ainda que 
em Maus o autor estiliza sua arte de modo a aparentar que os traços fossem desenhados dentro de um campo de concentração, e que tal conjugação entre estilo e contexto compõe a narrativa gráfica que se constrói na obra.

A arte de Spiegelman se relaciona intimamente com o conteúdo que o autor se propõe a narrar, de forma que cada recurso utilizado no desenho de cada quadro, ali se encontra com função representativa em relação ao que o autor quer transmitir e que transcende o espaço reservado para as palavras. Tudo aquilo que escapa da descrição verbal das caixas de texto dos quadrinhos, mas que se mostra imprescindível para a construção do discurso memorial é ilustrado por Spiegelman, de modo a emular a tensão pela qual seus pais e as demais vítimas do Holocausto estariam passando. Sobre os dados autobiográficos em uma produção literária do eu, Silviano Santiago afirma que:

\footnotetext{
Traduzem o contato reflexivo da subjetividade criadora com os fatos da realidade que me condicionam e os da existência que me conformam. Do ponto de vista da forma e do conteúdo, o discurso autobiográfico per se - na sua pureza - é tão proteiforme quanto camaleão e tão escorregadio quanto mercúrio (...) (SANTIAGO, 2008, p. 174)
}

O discurso do eu, por si só, é maleável e suscetível às nuances da existência individual e coletiva, de modo que se mostra preponderante no fazer literário autobiográfico o jogo de forças entre subjetividade e realidade. Sob uma perspectiva poética e antropológica, pode-se visualizar que não é o aspecto exterior que caracteriza as pessoas em Maus como reais, e sim as marcas de personalidade que cada individuo da obra possui, suas qualidades e defeitos, explicitados de igual forma, sem uma romantização dos acertos, nem tampouco uma atenuação dos erros. O comportamento racista do já idoso Vladek em relação a um homem afro-americano - representado como um esguio cachorro negro antropomorfizado -, já no final da obra, choca exatamente por demarcar a incongruência que existe na postura do pai do autor, sobrevivente de um massacre racial, em relação a outro grupo segregado ao longo da história da humanidade. A intolerância, o egoísmo e as diversas características que diferem os seres humanos uns dos outros, são o que movimentam a narrativa de Art Spiegelman.

A história da Segunda Guerra é, afinal, uma história sobre pessoas, e só a profundidade da representação humana conferiria à obra a densidade necessária para a exposição de um período tão acachapante da história da civilização moderna. Maus lida a todo instante com o distanciamento do sujeito e a busca do autor por identificação, por uma versão 
própria de seu passado, que o impactou e o modificou em seu processo de amadurecimento e crescimento psicológico. Spiegelman chega ao final de sua obra repetindo a forma como começou, alternando o passado com o presente, entrelaçando-os e buscando através deles uma reconciliação consigo mesmo. Ao mostrar o aparente final feliz de Vladek e Anja no passado, o autor coloca em segundo plano o suicídio de sua mãe, bem como o infarto que matou seu pai em 1982. Dessa forma, ele finda seu trabalho de busca por validação de sua própria história, tanto pessoal quanto familiar, e aceita seu lugar no mundo. O requadro final da obra, que mostra a lápide conjunta de seus pais, simboliza o final da jornada memorial de Art Spiegelman. Observa-se então que a escolha do autor pelas faces animais como representações de cada um dos povos retratados na obra dialoga alegoricamente com a paradoxal representação tácita daquilo que nos humaniza: nossas falhas e imperfeições.

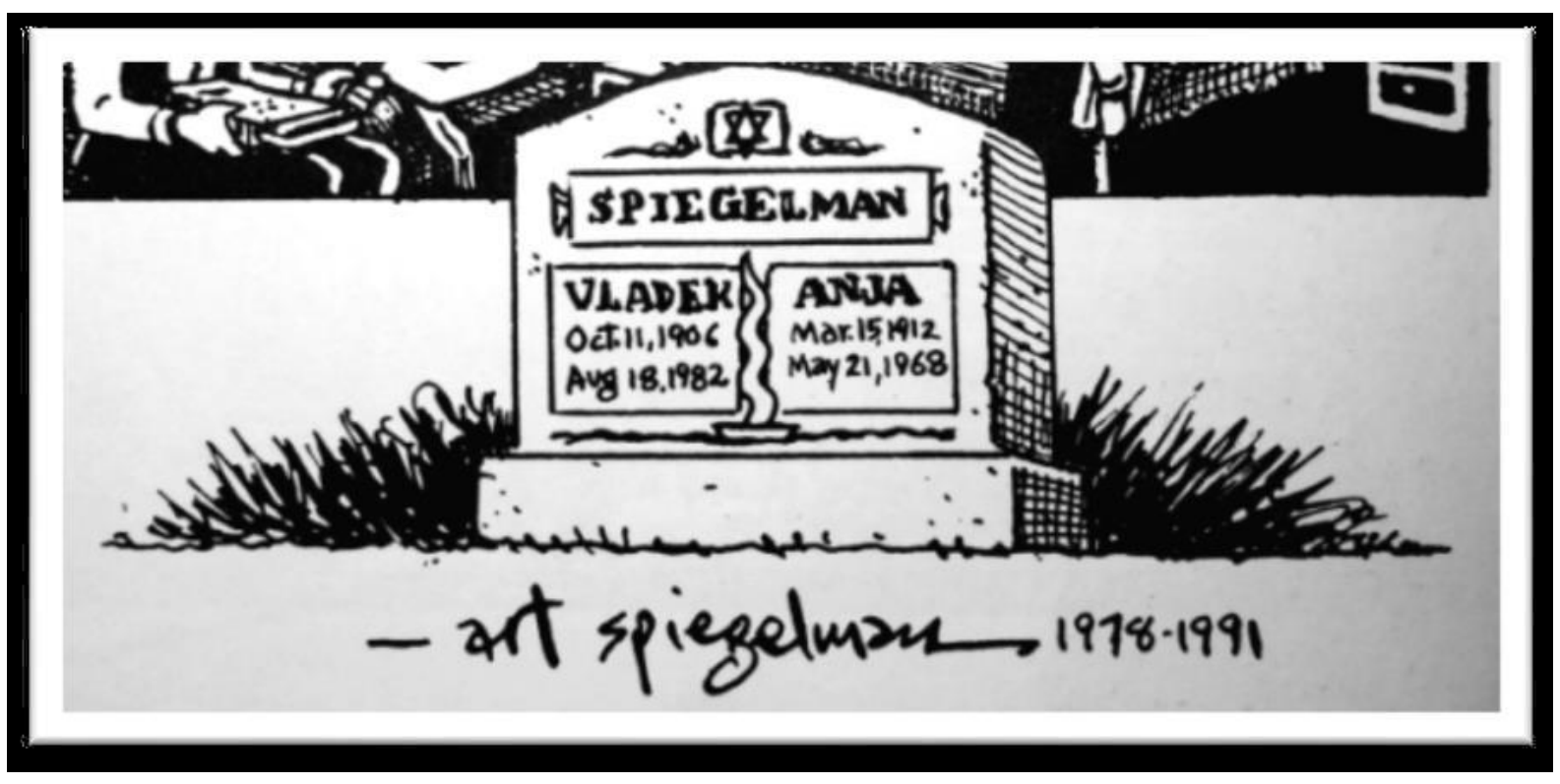

Figura 4: Fim do relato memorialista do autor. (SPIEGELMAN, 2009, p. 296)

\section{Considerações finais}

Com Maus, Art Spiegelman traçou um novo paradigma na concepção narrativa da arte sequencial, trazendo os holofotes para o surgimento das graphic novels como uma alternativa para o leitor de quadrinhos que não mais se identificava com as histórias de cunho infantil e/ou fantásticas. A abordagem autobiográfica empregada por Spiegelman se seguiu nos anos 
posteriores, através do trabalho de autores diversos ao redor do mundo, de modo que as barreiras entre ficção e realidade em relatos confessionais a cada vez mais se abrandaram. Tal processo conferiu validação artística para os narradores gráficos a partir de então, permitindoos a alçarem vôos cada vez mais altos em suas histórias, expandindo a miríade de possibilidades que possuem os quadrinhos para contarem seus relatos, sejam eles reais, ficcionais, ou um amálgama de ambos. As fronteiras entre o que se pode considerar como originário do campo do real, e o que se pode considerar pertencente ao campo imaginativo, se mostram cada vez mais uma questão de perspectiva do receptor. Afinal, como diria Alan Moore (1986), na introdução para sua idealização da última história do Superman: "Esta é uma história imaginária. Mas... não são todas elas?”

\section{Referências}

EISNER, Will. Narrativas gráficas de Will Eisner. Trad. Leandro Luigi Del Manto. São Paulo: Devir, 2013.

GARCÍA, Santiago. A novela gráfica. Trad. Magda Lopes. São Paulo: Martins Fontes - selo Martins, 2012.

LEJEUNE, Philippe. Definir autobiografía. In MOURÃO, Paula (Org.). Autobiografia. Autorepresentação. Lisboa: Colibri, 2003.

O pacto autobiográfico: de Rousseau à Internet. Trad. Jovita Maria Gerheim Noronha e Maria Inês Coimbra Guedes. Belo Horizonte: UFMG, 2008.

MCCLOUD, Scott. Desvendando os Quadrinhos. Trad. Helcio de Carvalho e Marisa do Nascimento Paro. $1^{\text {a }}$ ed. São Paulo: M. Books do Brasil, 2005.

MOORE, Alan. Superman: o que aconteceu ao homem de aço?. Trad. Jotapê Martins e Fabiano Denardin. 1ª ed. Barueri: Panini Books, 2013.

SANTIAGO, Silviano. Meditações sobre o ofício de criar. Aletria, 2008. Disponível em: <http://www.periodicos.letras.ufmg.br/index.php/aletria/article/viewFile/1450/1546>. Acesso em: 28 out. 2017.

SCHØLLHAMMER, Karl Erik. Ficção Brasileira Contemporânea. Rio de Janeiro:

Civilização Brasileira, 2009.

SPIEGELMAN, Art. Maus: a história de um sobrevivente. Tradução Antônio de Macedo Soares. São Paulo: Companhia das Letras, 2009. 
WALDMAN, Berta. Sobre gatos e ratos, autobiografia e biografia. In: LEWIN, Helena (Org.). Judaísmo e modernidade: suas múltiplas inter-relações. Disponível em: <http://books.scielo.org/id/ztpr5/pdf/lewin-9788579820168-27.pdf>. Acesso em: 28 out. de 2017. 